\title{
Adenosine to Thymidine Transversion Abnormality
}

National Cancer Institute

\section{Source}

National Cancer Institute. Adenosine to Thymidine Transversion Abnormality. NCI

Thesaurus. Code C45644.

A point mutation involving the substitution of Thymidine (a pyrimidine base) for

Adenosine (a purine base) in a DNA sequence from eukaryotic or prokaryotic org anisms.

This abnormality can be either heritable or occur somatically. 